\title{
Las palabras culturales en las traducciones al esloveno de las obras de Juan Rulfo y Carlos Fuentes $^{1}$
}

Palabras clave: traducción, palabras culturales, extranjerización, literatura hispanoamericana, esloveno

\section{Introducción}

En el artículo se analizan las palabras culturales en las traducciones eslovenas de la novela Pedro Páramo y de algunos cuentos de El Llano en llamas de Juan Rulfo (publicados en el mismo libro) y de la novela La muerte de Artemio Cruz $z^{3}$ de Carlos Fuentes. Todos los textos estudiados fueron traducidos al esloveno en la misma década: en los años setenta del siglo XX por la misma traductora, Alenka Bole Vrabec: Pedro Páramo (con una selección de cuentos de El Llano en llamas) en 1970 y Smrt Artemia Cruza en 1977. Eso me ha dado la posibilidad de comparar los procedimientos de traducción y deducir el estilo personal de la traductora. ${ }^{4}$

$1 \quad$ Este artículo es la presentación de la tesis de maestría de la autora (escrita originalmente en esloveno: Kulturno besedje v slovenskib prevodib del Juana Rulfa in Carlosa Fuentesa) dirigida por la dra. Jasmina Markič de la Universidad de Ljubljana.

2 En las referencias a la novela Pedro Páramo uso la abreviatura PP para el texto original y la abreviatura PPS para la traducción al esloveno. En las referencias a los cuentos del libro de cuentos El Llano en llamas uso la abreviatura LL para el texto original y PPS-LL para la traducción al esloveno (los cuentos añadidos a la novela Pedro Páramo).

3 En las referencias a la novela La muerte de Artemio Cruz uso la abreviatura MAC para el texto original (La muerte de Artemio Cruz) y la abreviatura SAC para la traducción al esloveno (Smrt Artemia Cruza).

4 Para la explicación del concepto del estilo personal del traductor ver Martina Ožbot, 2002: 188. 
El propósito de este artículo no es valorar las decisiones de la traductora, sino analizar los procedimientos de traducción de las palabras culturales y su funcionamiento dentro del texto meta ( coherencia del texto o no). La hipótesis plantea si las estrategias de la traductora reflejaban también el conocimiento de los realia mexicanos, las expectativas del sistema literario esloveno y los acuerdos sobre la traducción en el lugar meta en un período determinado.

\section{Las palabras culturales}

Las palabras culturales ${ }^{5}$ (o los realia ${ }^{6}$ ) son términos que denotan objetos, conceptos y fenómenos típicos de una determinada cultura y no tienen equivalentes en otras culturas (en nuestro caso en la cultura eslovena), es decir, carecen de una traducción precisa en otras lenguas. Son palabras (y locuciones compuestas) que representan denominaciones de objetos, conceptos, fenómenos típicos de un ambiente geográfico, de la vida material de una cultura (por ejemplo flora y fauna, comida y bebida, características geográficas, ropa y otros elementos etnográficos) y que por esto son portadoras de un colorido nacional o local (Zakrajšek, 2002: 424).

Las palabras culturales son también aquellos elementos que le dan al texto meta un carácter extranjerizante, muestran claramente que se trata de una traducción (Florin, 1993: 122) y nos presentan el mundo narrado como un mundo exótico y desconocido. El traductor debe encontrar una estrategia para incluir este léxico en el texto meta lo más adecuado posible.

Hay que señalar que las palabras culturales no aparecen aisladas, sino dentro del contexto. Si no entendemos una palabra o una frase (o no las entendemos bien), eso no quiere decir que no las entenderíamos dentro del contexto. En el dilema de si en la traducción es mejor transferir una palabra cultural o sustituirla por una palabra equivalente aproximada Florin dice que el traductor tiene que pensar qué método asegura una pérdida mínima combinada con la comunicación máxima (Florin, 1993: 126).

$5 \quad$ Ver también Shuttleworth (1997), Florin (1993), Vevar (2001, 2013), Bajt (1997), Newmark (2004), Zakrajšek (2000, 2002).

6 Del latín realis. 


\section{Las palabras culturales en la traducción}

Las obras analizadas de Juan Rulfo y Carlos Fuentes difieren en cuanto a las técnicas narrativas, pero suponen el mundo del texto muy parecido (la búsqueda de la mexicanidad). El lector que sea ajeno al mundo real mexicano se siente inmerso en un mundo distinto de su civilización y cultura; penetra en un mundo que le resulta lejano. Hay gran cantidad de palabras culturales mexicanas por eso mi propósito ha sido observar cómo la traductora incorpora en el texto meta este léxico sin equivalencia en el esloveno. También en la versión original de los textos publicados en España a pie de página se recogen notas explicativas referentes a las palabras culturales mexicanas (y otras aclaraciones de tipo cultural o histórico).

He comparado ciertos ejemplos del texto original y del texto meta (qué proviene del original y qué aporta la traducción). Me he centrado en los realia referentes a comida y bebida, ropa, animales, plantas y otro léxico ligado a la casa y la vida rural.

El traductor tiene que evaluar si la cultura receptora se inclina a absorber palabras extranjeras. Debe elegir si optar por una mayor o menor visibilidad de la cultura originaria del texto. También tiene que saber a quién se dirige el texto para poder evaluar cuál es la mejor estrategia traductiva de los realia. Es esencial tener presente también el grado de conocimiento de una entidad ajena en la comunidad receptora o, si existe, cuál es su transcripción (Florin, 1993: 126, 127).

\section{Lengua meta}

Una de las muestras de dicho conocimiento podrían ser los diccionarios. En los años setenta del siglo XX ya existía el Diccionario Español-Esloveno de Anton Grad. Al mismo tiempo tenemos que tener en cuenta que los diccionarios siempre llevan cierto retraso en cuanto a la realidad lingüística.

Mis suposiciones acerca de otras posibles estrategias traductivas (si la traductora podría optar por un equivalente esloveno o, por lo menos, por la transcripción domesticada de las palabras culturales extranjeras) las basaba en el Diccionario de la Lengua Eslovena Estándar (SSKJ) que salía en la misma época que las traducciones analizadas en este artículo. La traductora todavía no podía usarlo, pero a pesar de eso lo considero una muestra representativa de la ocurrencia del léxico en los textos de aquel entonces. 
Si suponemos que una determinada palabra figura en el Diccionario de la Lengua Eslovena Estándar ( $S S K J$ ) porque se ha documentado cierta difusión de dicha expresión en las fuentes usadas, eso quiere decir que, cuando los traductores consultan dicho diccionario ( $S S K J$ ), parten de una serie de textos que presentan el mundo del texto semejante al texto que están traduciendo. Y si una palabra figura en $S S K J$, eso quiere decir que aparece en un número considerable de textos.

En el prólogo no se explica según qué criterio se incorporaron los extranjerismos y los realia en el diccionario (SSKJ); solamente podemos encontrar la regla de escritura: en el caso de extranjerismos se acepta la escritura que prevalecía en el período de la redacción.

Cuando el traductor decide introducir en el texto meta una palabra cultural extranjera, tiene que seguir las reglas de la lengua meta. En la lengua eslovena los préstamos léxicos los adaptamos al esloveno en la pronunciación, morfología y sintaxis, en la escritura optamos por la adaptación total o parcial. Los préstamos léxicos comunes los escribimos con las grafías eslovenas tal como los pronunciamos, por ejemplo mačeta, mačizem, tortilja, tekila.

\section{Extranjerización}

El análisis de las palabras culturales en las traducciones de Bole Vrabec muestra la tendencia a la extranjerización, o bien, a acentuar lo extraño, lo exótico del mundo del texto. La extranjerización ${ }^{7}$ supone que en una traducción los elementos de la cultura de origen se mantienen en la mayor manera posible, mientras que hablamos de la domesticación ${ }^{8}$ cuando esos se tienden a borrar (Ožbot, 2012: 57). Al mismo tiempo hay que señalar que también el texto original puede llevar cierto ímpetu extranjerizante ya que sus lectores pertenecen a diferentes culturas hispanohablantes.

Friedrich Schleiermacher, uno de los más destacados teóricos de la traducción en la corriente hermenéutica, publicó Sobre los diferentes métodos de traducir en 1813. Sostenía que hay dos maneras básicas de traducir: «O bien el traductor deja al escritor lo más tranquilo posible y hace que el lector vaya a su encuentro, o bien deja lo más tranquilo posible al lector y hace que vaya a su encuentro el escritor» (Ordóñez López, 2009: 105, Schleiermacher, 2000: 47). En el primer caso, el traductor elabora una traducción extranjerizante; en el

7 Venuti $(1995,1998)$ usa los términos exoticizing y foreignizing translation.

8 Venuti (1995, 1998) utiliza los términos fluent, invisible, assimilating y etbnocentric translation. 
segundo, la traducción se habrá aclimatado a la cultura receptora, es decir, se trata de localizar la traducción.

Ortega y Gasset opta por la traducción extranjerizante. En su ensayo Miseria y esplendor de la traducción defiende un estilo de traducir que pone de relieve las peculiaridades de la cultura de origen en el texto meta: un método que se suele identificar con la teoría contemporánea de la traducción con el concepto de la extranjerización de Lawrence Venuti: «Lo decisivo es que, al traducir, procuremos salir de nuestra lengua a las ajenas, y no al revés, que es lo que suele hacerse» (Ortega y Gasset, 1950: 146).

Para Ortega y Gasset la traducción no es la obra, sino un camino hacia la obra: «La traducción no es un doble del texto original; no es, no debe querer ser la obra misma con léxico distinto» (1950: 142). Piensa que necesitamos aprender de los autores antiguos muchas cosas para utilizarlas con plena actualidad. Necesitamos de ellos precisamente en cuanto son disímiles de nosotros, y la traducción debe subrayar su carácter exótico y distante (1950: 146-147).

Miguel Montezanti afirma que Ortega y Gasset se habría convertido en precursor de Venuti. Los dos autores argumentan a favor de la extranjerización, aunque con las respectivas diferencias. Ortega y Gasset se afinaría por «discernir el sentido histórico y erróneo del hombre» con fines pedagógicos, mientras que Venuti proclamaría «una resistencia contra el etnocentrismo y racismo, el narcisismo y el imperialismo» (Montezanti, 2000: 40 - citado por Ordóñez López, 2009: 170, 171).

Lawrence Venuti se opone al deseo de conseguir la lectura fluida y fácil del texto traducido que, según su opinión, puede causar una adaptación excesiva de la traducción a la cultura y lectores meta y opta por una traducción extranjerizante. Una traducción fluida, según Venuti, crea la ilusión de leer el texto original, no la traducción.

La cultura angloamericana ha sido dominada durante mucho tiempo por las teorías de la domesticación que recomiendan una traducción fluida. Para Venuti, al producir la ilusión de la transparencia, una traducción fluida se hace pasar por verdadera equivalencia semántica cuando, de hecho, debería expresar lo extranjero y diferente del texto original (Venuti, 1995: 21). Martina Ožbot constata que la literatura eslovena (al igual que otros sistemas periféricos) se inclina a retener los elementos extranjeros, sobre todo a nivel del léxico (Ožbot, 2012: 58). 


\section{El traductor como mediador intercultural}

Octavio Paz afirma en Traducción: literatura y literalidad que «cada lengua es una visión del mundo» (Paz, 1971: 2). ${ }^{9}$ También por eso traducir es una tarea difícil: del traductor se exigen muchos conocimientos (debe conocer tanto el idioma de origen y de destino como la cultura de origen y de destino) pero al mismo tiempo tiene el derecho de tomar sus propias decisiones a la hora de componer un nuevo texto (Miklič, 1999: 22).

El traductor traduce para un público determinado. Si trata de abolir los extranjerismos con el fin de que sus receptores no tengan ningún problema en descodificar el texto con eso puede desdibujar la sensación de extrañeza, el interés por otras culturas y otras gentes (Moya, 2004: 55).

\section{Entre la extrañeza y la extranjerización}

Una prueba de que el lector en la literatura busca otros mundos, lo lejano y lo ajeno, es sin duda el boom latinoamericano cuando el trabajo de los novelistas latinoamericanos fue ampliamente traducido y distribuido en Europa y en todo el mundo. Sus novelas que reciben también los más destacados premios literarios atraen a los lectores porque son diferentes. Resulta destacable que los propios escritores hispanoamericanos se dieron cuenta de la magia de su mundo (americano) cuando vivían en Europa, es decir, después de sus experiencias europeas. Una traducción domesticada de esas obras no habría complacido al público.

En Eslovenia, las traducciones de los textos del boom latinoamericano coincidieron con las traducciones de estas obras en otras partes de Europa y América. Durante esa época se tradujeron también las obras analizadas en este artículo y van acompañadas del entusiasmo de la traductora por el sonido de la lengua española y por la realidad mexicana. Es probable que esto influyera en la lectura de la traductora y en sus decisiones al traducir.

En las traducciones analizadas noté tal tendencia a la extranjerización, deseando crear condiciones para la extrañeza ante un mundo exótico y al mismo tiempo el deseo de explicar lo ajeno para que los lectores puedan imaginarse tal realidad.

9 Barcelona: Tusquets, 1971. Para este artículo he usado el texto en versión electrónica. Como las páginas no llevaban números, las he enumerado para localizar la frase citada (de 1 a 10). 


\section{Estrategias extranjerizantes en las traducciones analizadas}

Cuando una palabra cultural extranjera ha entrado en el esloveno estándar (avokado, tortilja, tekila) adaptando la morfología, la fonética y la escritura a mecanismos de expresión propios de la lengua receptora (el esloveno), eso indica una mayor integración del producto en la sociedad receptora. Si la dejamos en su forma original (en nuestro caso española), queremos subrayar el carácter extraño, exótico de la realidad, lo cual contribuye a la extranjerización. En los textos literarios así podemos arrancar a los lectores de su percepción automatizada y cotidiana y creamos la sensación de extrañamiento ante el mundo, lo cual debería ser el propósito del arte según Víktor Shklovski (Šklovski, 2010: 13, 14).

En los textos analizados hay gran cantidad de términos (entre ellos también palabras culturales referentes a animales, plantas, costumbres, comida, accidentes geográficos típicos de México) que pueden resultar desconocidos incluso al lector de habla española que no conozca el medio ambiente hispanoamericano en general y el mexicano en particular. Sin embargo, resulta interesante que el lector en la mayoría de estos casos no se siente desorientado porque en el texto hay suficientes referencias que ayudan a entender lo esencial.

La traductora de los textos analizados, Alenka Bole Vrabec, en el caso de las palabras culturales normalmente elige la transferencia con el fin de reflejar el colorido y el ambiente locales, incluso cuando podría encontrar equivalentes en esloveno o, por lo menos, adaptar las palabras a la escritura de acuerdo con las reglas del esloveno. Estas decisiones acentúan el carácter extranjerizante de sus traducciones. Al mismo tiempo la traductora suele explicar el significado de dichas palabras culturales en un glosario al final de la novela (en Pedro Páramo) o en las notas a pie de página (en Smrt Artemia Cruza).

En la mayoría de los casos este léxico (tanto en el texto original ${ }^{10}$ como en la traducción) no impide el entendimiento, el lector no se siente desorientado porque hay referencias muy claras por las que, aunque no conozcamos el significado del vocablo, comprendemos lo esencial del mismo. Comprendemos que se trata, por ejemplo, de un plato, una bebida, un pájaro, por eso el texto a nivel microestructual ${ }^{11}$ es coherente. ${ }^{12}$

10 No todos los lectores de habla hispana conocen el medio ambiente mexicano, por eso les resultarán desconocidos gran cantidad de términos que aparecen en los textos (originales) analizados.

11 A nivel de frase, oración, párrafo.

12 «La coherencia no es un simple rasgo que aparezca en los textos, sino que se trata más bien de un producto de los procesos cognitivos puestos en funcionamiento por los usuarios de 
En el ejemplo (1) se ve claramente que cezontle es un pájaro.

(1) Ella, como todas las tardes, recorrió las jaulas coloradas del patio, cubriéndolas con capuchas de lona después de observar los movimientos nerviosos de los cezontles y petirrojos que picoteaban el alpiste y chirriaban, por última vez, antes de que el sol desapareciera (MAC, 154).

Vstala je in se kot vsako popoldne sprehodila med pisanimi ptičjimi kletkami v patiu in jih prekrila $\mathrm{z}$ jadrovinastimi pregrinjali, potem ko se je nagledala cezontlov in taščic, ki so nemirno kljuvali zrnje in še zadnjič zagostoleli, preden je sonce zašlo (SAC, 53 ).

*cezontle: ptica, ki zelo lepo poje (SAC, 53).

En la novela Smrt Artemia Cruza no todas las palabras culturales mexicanas tienen una referencia muy clara en el contexto, por eso las explicaciones en las notas a pie de página ayudan mucho al lector. Eso pasa sobre todo donde el monólogo de Artemio Cruz adopta un tono ensayístico y se plantean las grandes cuestiones sobre México y los mexicanos, como en el ejemplo (2). E1 lector tiene la sensación de que se está perdiendo en el torbellino de la historia de México. Estos pasajes son difíciles de entender (tanto en el original como en la traducción) debido a las técnicas narrativas del autor y no tanto a los realia.

(2) Traerás los desiertos rojos [...], la carne chaparra de Tlaxcala, los ojos claros de Sinaloa, los dientes blancos de Chiapas, los buipiles, las peinetas jarochas, las trenzas mixtecas, los cinturones tzotziles, los rebozos de Santa María [...] (MAC, 365, 366).

V sebi boš nosil rdeče puščave [...], čokata telesa iz Tlaxcale, jasne oči iz Sinaloe, buipile, bele zobe iz Chiapasa, glavnike iz Veracruza, mixteške kite, pasove Tzotilov, reboze iz Santa Marie [...] (SAC, 290, 291).

*huipil: okrašena srajca brez rokavov, ki jo nosijo Indijanke (SAC, 291).

*rebozo: ogrinjalo, s katerim je navadno zastrt tudi obraz (SAC, 86).

Bole Vrabec mantiene la atmósfera de lo extraño y exótico del texto original sobre todo con la transferencia de las palabras culturales, como podemos ver en los ejemplos (3) y (4), donde la traductora decide mantener la forma española de las palabras culturales (y en cursiva) papaya, macbeta y tortilla, aunque

los textos. [...] Un texto no tiene sentido por sí mismo, sino gracias a la interacción que se establece entre el conocimiento presentado en el texto y el conocimiento del mundo almacenado en la memoria de los interlocutores» (Beaugrande y Dressler, 1997: 39, 40). 
en el Diccionario de la Lengua Eslovena Estándar (SSKJ) ya figuran los vocablos adaptados en la escritura eslovena: papaja, mačeta y tortilja. Se trata de un elemento extranjerizante en el texto meta. Pensando en los lectores, Bole Vrabec en el ejemplo (3) inserta una información adicional ya dentro del texto meta (que se trata de un cuchillo y un fruto) y explica el significado también en las notas a pie de página.

(3) Lunero ya estaba friendo el pescado y abriendo una papaya con el machete (MAC, 377).

Lunero je že pekel ribo in z macheto razsekal sadež papaye (SAC, 303).

*macheta: južnoameriško orodje in orožje, podobno handžarju (SAC, 64).

*papaya: tropski sadež slastnega okusa (SAC, 160).

(4) ¡Con decirle que se comía mis mismas tortillas y que las embarraba en mi mismo plato (LL, 65)!

Če vam povem, da je pojedel moje lastne tortille in si jih namazal na mojem krožniku (PPS-LL, 172)!

* tortilla: koruzni hlebček (PPS, 238)

Desde este punto de vista los textos meta analizados son altamente extranjerizantes. Bole Vrabec acentúa la impresión de una atmósfera extraña aún más con el uso de los préstamos léxicos, en vez de traducir las palabras que tienen sus equivalentes muy claros en la lengua meta.

(5) Y así poco a poco la cosa se convirtió en fiesta. Comala hormigueó de gente, de jolgorio y de ruidos, igual que en los días de la función en que costaba trabajo dar un paso por el pueblo $(\mathrm{PP}, 186)$.

In tako se je vse skupaj pomalem spremenilo v fiesto. V Comali je mrgolelo ljudi, bilo je hrupno in veselo kot ob proščenjih, ko se človek komaj prerine skozi vaške ulice (PPS, 120).

En todas las traducciones analizadas, Bole Vrabec opta por no traducir la palabra española patio sino por dejarla en su forma española con las desinencias eslovenas (y en cursiva). En los ejemplos se nota la referencia al lugar (al lado de la casa) pero, a pesar de eso, podría utilizar simplemente la expresión eslovena dentro del texto (no solo en la nota a pie de página):

(6) Y era fácil ver cuántos montones de maíz y de calabazas amarillas amanecían asoleándose en los patios (LL, 46). 
In sleherno jutro so bili vsem na očeh številni kupi koruze in rumenih buč, ki so se sušile v patiih (PPS-LL, 145, 146).

*patio: notranje dvorišče (PPS, 238)

En la novela Smrt Artemia Cruza la traductora utiliza constantemente la palabra española moskito (adaptada al esloveno en la escritura) en vez de komar (sin explicación en una nota a pie de página; en el ejemplo (7) la palabra roj (enjambre) muestra que se trata de un insecto).

(7) Don Gamaliel, con la servilleta, espantó los mosquitos que volaban alrededor del frutero real, menos abundante que el pintado (MAC, 146).

Don Gamaliel je s prtičem odgnal roj moskitov, ki so plesali okoli posode za sadje, precej manj naložene od tiste na sliki (SAC, 45).

\section{$8 \quad$ La integración de los cultivos y otros productos extranjeros en la cultura meta}

En los textos analizados abunda el léxico cuyo uso se circunscribe a México, por eso no es de esperar que sea conocido en el lugar meta. Creía que las elecciones de los procedimientos de traducción de Bole Vrabec reflejaban la integración real o el conocimiento de los cultivos y otros productos extranjeros en la cultura meta en la época en la que se produjo la traducción. Sin embargo, no hay que sacar conclusiones prematuras puesto que la traductora, deseando crear una sensación extranjerizante, a veces utiliza el préstamo léxico aunque en la lengua meta ya se ha consolidado cierta palabra para nombrar un cultivo u otro producto extranjero. En la traducción de la novela Pedro Páramo Bole Vrabec opta por no traducir la palabra maguey aunque en la cultura receptora se ha consolidado la palabra eslovena agava (figura también en el Diccionario de la Lengua Eslovena Estándar $S S K J)$, que, curiosamente, ella misma introduce en el glosario al final del libro.

(8) Si al menos hubiéramos traído tantito pulque, no importaría; pero el cogollo de los magueyes está hecho un mar de agua. (PP, 156)

*maguey: planta propia de las tierras altas y secas. Se conocen cerca de doscientas especies. Algunas se cultivan especialmente para la fabricación de bebidas fermentadas (PP, 156).

Ko bi bili prinesli vsaj požirek pulqueja, bi nam bilo kaj malo mar; toda mladi poganjki magueyev so se spremenili v jezero (PPS, 90).

*maguey: agava (PPS, 238) 
En Smrt Artemia Cruza, en el caso de la palabra cultural maguey, la traductora no sigue una línea general. En la mayoría de los casos se usa la expresión eslovena (ejemplo 9), pero no siempre (como en el ejemplo 10).

(9) Los flancos de maguey impedían salirse del camino para dar un rodeo y la mujer blanca se defendía del sol con la sombrilla entre los dedos [...] (MAC, 209).

Agave, ki so z obeh strani obdajale cesto, so mu branile, da bi naredil ovinek čez polja, belopolta ženska pa si je pred žarkim soncem varovala obraz s sončnikom [...] (SAC, 114).

(10) [...] la media luna veracruzana tendrá otra historia, atada por hilos dorados a las Antillas [...] que en verdad sólo será vencido por los contrafuertes de la Sierra Madre Oriental: donde los volcanes se anudan y las insignias silenciosas del maguey se levantan [...] (MAC, 369)

[...] veracruzški polmesec pa si želi drugačno zgodovino in je z zlatimi nitmi povezan z Antili [...], ki ga v resnici zastavi šele predgorje vzhodne Sierre Madre: kjer se pnejo v nebo vulkani in molčeča znamenja magueyev [...] (SAC, 294)

Tampoco los procedimientos de traducción para la palabra cultural mexicana chile en los textos analizados reflejan el (des)conocimiento real del cultivo extraño en la cultura eslovena en la época en la que se produjo la traducción. En la traducción de la novela Pedro Páramo Bole Vrabec traduce la palabra chile: usa la expresión eslovena buda paprika (ejemplo 11); en la novela Smrt Artemia Cruza (que fue publicada siete años más tarde que Pedro Páramo) opta por mantener el préstamo léxico y por dejarlo en su forma española (chile). En la nota a pie de página lo traduce de forma incorrecta (ejemplo 12). Čili no es una pimienta (zelo pekoč poper), sino un pimiento. Una vez seco se puede moler y queda un polvo picante para condimentar (ejemplo 12).

(11) Total, es dinero lo que necesitamos para mercar aunque sea una gorda con chile (PP, 177-178).

*cbile: (del nahua chilli) pimiento. Hay muchas variedades y su consumo es muy grande en México (PP, 178).

Skratka, potrebujemo denar, pa čeprav samo toliko, da si kupimo tortillo s budo papriko (PPS, 111). 
(12) Metió el cucharón en el caldo hirviente del menudo, pellizcó la cebolla, el chile en polvo, el orégano; masticó las tortillas norteñas, duras, frescas; las patas de cerdo (MAC, 187).

*el chile es pimiento picante (MAC, 187).

Z leseno zajemalko si je natočil vročo juho iz drobovine, odščipnil kos čebule in potresel juho s chilejem in divjim majaronom, in žvečil tortille s severa, sveže, hrustljave, obiral svinjske parklje (SAC, 89).

*chile: zelo pekoč poper (SAC, 187).

\section{Conclusión}

Alenka Bole Vrabec quiere mantener en sus traducciones un cierto sabor español en el lenguaje y la impresión de una atmósfera lejana y extraña al ambiente esloveno. Su decisión por una traducción extranjerizante no sorprende mucho, ya que Alenka Bole Vrabec se siente cautivada por la melodía de la lengua española y la realidad latinoamericana. Este encanto lo quiere transmitir a los lectores eslovenos. En la mayoría de los casos opta por la transferencia de las palabras culturales extranjeras y a menudo introduce la información adicional en las notas a pie de página (en Smrt Artemia Cruza) o en un glosario al final del libro (en Pedro Páramo y los cuentos de El Llano en llamas).

Sería interesante investigar la recepción de la literatura traducida entre los lectores eslovenos (por qué la leen, si leen las informaciones adicionales en el glosario o las notas a pie de página, si el desconocimiento de una cultura dificulta la lectura o llama a la lectura, etc.).

\section{Bibliografía}

Bajec, A., Kolarič R. et al. (1962): Slovenski pravopis (SP). Ljubljana: Državna založba Slovenije.

Bajt, D. (1997): «Prevod kot objektivizacija subjektivnih meril». En: Majda Stanovnik (ed.), 21. zbornik Društva slovenskib književnib prevajalcev, 42-49.

Beaugrande, R. A., Dressler W. U. (1997): Introducción a la lingüística del texto. Barcelona: Editorial Ariel, S. A.

Blanco Aguinaga, C. (2006): «Introducción». En: Juan Rulfo, El Llano en llamas. Madrid: Cátedra, 9-32. 
Bole Vrabec, A. (1993): «Avtobiografski prevajalski kroki». En: Majda Stanovnik (ed.), 17. zbornik Društva slovenskib književnib prevajalcev, 66-69.

Florin, S. (1993): «Realia in translation». En: Palma Zlateva (ed.), Translation as Social Action. London/New York: Routledge, 122-128.

González Boixo, J. C. (1983): Claves narrativas de Juan Rulfo. León: Universidad de León.

González Boixo, J. C. (1995): «Introducción». En: Juan Rulfo, El Llano en llamas. Madrid: Cátedra, 9-6o.

González Boixo, J. C. (1995b): «Introducción». En: Carlos Fuentes, La muerte de Artemio Cruz. Madrid: Cátedra, 9-99.

Grad, A. (1984): Špansko-slovenski slovar. Ljubljana: Državna založba Slovenije. Iaculli, Gabriel (2006): «Decir lo implícito: traducir „El Llano en llamas“ y „Pedro Páramo“». En: Victor Jiménez, Albert Vital, Jorge Zepeda (ed.), Tríptico para Juan Rulfo: México: SM.

Kastelic Vukadinović, U. (2006): «Slogovni premiki v prevodu romana Carlos Fuentesa „Smrt Artemia Cruza“». En: Vestnik 40/1-2. Ljubljana: Društvo za tuje jezike in književnosti Slovenije, 95-108.

Kastelic Vukadinović, U. (2016): Kulturno besedje v slovenskib prevodib del Juana Rulfa in Carlosa Fuentesa: tesis de maestría inédita. Ljubljana: Filozofska fakulteta.

López Mena, S. (ed.) (1999): Cómo traducir la obra de Juan Rulfo. México, D. F.: Editorial Praxis.

Markič, J. (2007): «Interculturalidad y comunicación: aspectos lingüísticos y socio-culturales de la traducción literaria entre el español y el esloveno». En: A. Pamies Bertrán, J. de Dios Luque Durán (ed.), Interculturalidad y lenguaje II. Granada: Granada Lingüística, 309-318.

Miklič, T. (1999): «Prevajalec naj lepo samo prevede tisto, kar tam piše: O prevajalčevi vlogi v komunikacijeskem procesu». En: Irena Kovačič e Inka Štrukelj (ed.), Uporabno jezikoslovje 7-8 (Tematska številka Prevajanje in tolmačenje). Ljubljana, 10-24.

Moya, V. (2004): La selva de la traducción: Teorías traductológicas contemporáneas. Madrid: Cátedra.

Newmark, P. (2004): Manual de traducción. Madrid: Cátedra.

Ordóñez López, P. (2009): Miseria y esplendor de la traducción: La influencia de Ortega en la traductología contemporánea. Castelló de la Plana: Universitat Jaume I. 
Ortega y Gasset, J. (1950): El libro de las misiones. Buenos Aires: Espasa Calpe, $113-147$.

Ožbot, M. (2002): «Machiavelli in Boccaccio v Koširjevih oblačilih: k vprašanju prevajalčevega osebnega sloga». En: Martina Ožbot (ed.), Prevajanje srednjeveškib in renesančnib besedil (27. prevajalski zbornik). Ljubljana: Društvo slovenskih književnih prevajalcev, 187-199.

Ožbot, M. (2012): Prevodne zgodbe: poskusi z zgodovino in teorijo prevajanja s posebnim ozirom na slovensko-italijanske odnose. Ljubljana: Založba ZRC, ZRS SAZU (Studia translatoria 4).

Paz, O. (1971): Traducción: literatura y literalidad. Barcelona: Tusquets. http:// www.cervantesvirtual.com/obra/traduccion-literatura-y-literalidad/ $(30-3-2016)$.

Schleiermacher, F. (2003): «O različnih metodah prevajanja». En: Nike Kocijančič Pokorn, Misliti prevod. Ljubljana: Študentska založba (Knjižna zbirka Skripta), 54-57.

Shuttleworth, M. (1997): Dictionary of Translation Studies. Manchester: St Jerome Press, 139-140.

Šklovski, V. (2010): Teorija proze. Koper: Hyperion.

Toporišič, J. et al. (2001): Slovenski pravopis (SP). Ljubljana: Založba ZRC, ZRC SAZU.

Venuti, L. (1995): The Translator's Invisibility: A History of Translation. London/ New York: Routledge.

Venuti, L. (1998): The Scandals of Translation: Towards an Etbics of Difference. London/New York: Routledge.

Venuti, L. (2003): «Nevidnost prevajalca». En: Nike Kocijančič Pokorn, Misliti prevod. Ljubljana: Študentska založba (Knjižna zbirka Skripta), 249-253.

Vevar, Š. (2001): Temeljni aspekti in principi teorije literarnega prevajanja. Ljubljana: Študentska založba.

Vevar, Š. (2013): Vrvobodska umetnost prevajanja. Ljubljana: Cankarjeva založba.

Witte, H. (2008): Traducción y percepción intercultural. Granada: Editorial Comares (Interlingua 70).

Zakrajšek, K. (2000): «Kultura in slovar (prevajanje slovenskega kulturološkega besedja)». En: 36. SSJLK, 365-375. 
Zakrajšek, K. (2002): «Kulturno in zgodovinsko obarvano besedje in dvojezični slovar». En: Historizem v raziskovanju slovenskega jezika, literature in kulture (Obdobja 18). Ljubljana: Filozofska fakulteta, 423-431.

Zakrajšek, K. (2009): «Potujitveni in prisvajajoči prevod v luči medjezikovnih razmerij moči». En: Hieronymus 3, št. 1/2. Ljubljana: Društvo slovenskih književnih prevajalcev, 7-21.

ZRC SAZU, Inštitut za slovenski jezik Frana Ramovša (1995): Slovar slovenskega knjižnega jezika (SSKJ). Ljubljana: DZS.

\section{Corpus}

Rulfo, J. [1953] (2006): El Llano en llamas (LL). Madrid: Cátedra.

Rulfo, J. [1955] (1995): Pedro Páramo (PP). Madrid: Cátedra.

Fuentes, C. [1962] (1995): La muerte de Artemio Cruz (MAC). Madrid: Cátedra.

Rulfo, J. (1970): Pedro Páramo (PPS y PPS-LL). Ljubljana: Cankarjeva založba.

Fuentes, C. (1977): Smrt Artemia Cruza (SAC). Murska Sobota: Pomurska založba. 
Uršula Kastelic Vukadinović

Lyceum Jože Plečnik Ljubljana

\section{Cultural Words in Slovenian Translations of the Works of Juan Rulfo and Carlos Fuentes}

Keywords: translation, cultural words, foreignization, Spanish American literature, Slovenian.

The paper, based on the author's thesis entitled Kulturno besedje $v$ slovenskib prevodib del Juana Rulfa in Carlosa Fuentesa, discusses cultural words in the Slovenian translations of the novel Pedro Páramo, some of the stories of The Plain in Flames by Juan Rulfo published in the same volume and the novel The Death of Artemio Cruz by Carlos Fuentes. In the analyzed texts there are a number of terms (also including cultural words which denote animals, plants, dishes, clothes and geographical surroundings of Mexico) that may be unknown even to the Spanish speaking readers who are not familiar with the wider Hispanic environment, and Mexican in particular. Cultural words have no exact equivalents in other languages and cultures, therefore, they most commonly indicate that we are reading a translated text. These are also the elements that contribute to the foreignization of the target text and show us the textual world as exotic and unknown. The translator of the studied texts, Alenka Bole Vrabec, tends to choose the transfer of the cultural words in order to retain some local colour, even when she could find equivalents in the Slovenian or, at least, adapt the words to the writing in accordance with the rules of the Slovenian language. These decisions accentuate the foreignizing character of her translations. 
Uršula Kastelic Vukadinović

Gimnazija Jožeta Plečnika Ljubljana

\section{Kulturno besedje v slovenskih prevodih del Juana Rulfa in Carlosa Fuentesa}

Ključnebesede:prevajanje, kulturnobesedje, potujevanje, hispanoameriška literatura, slovenščina

Prispevek, ki temelji na avtoričinem magistrskem delu, obravnava mehiško kulturno besedje v slovenskem prevodu romana Juana Rulfa Pedro Páramo z dodanim izborom novel iz zbirke El Llano en llamas in v slovenskem prevodu romana Carlosa Fuentesa Smrt Artemia Cruza. Obravnavana mehiška literarna besedila so kulturno obarvana in med drugim prinašajo obsežno besedje, ki v slovenskem jeziku in kulturi nima ekvivalentov. Gre za kulturno besedje, ki poimenuje živali, rastline, oblačila, tradicionalne jedi, pijače in druge izraze, ki se uporabljajo le na omejenem zemljepisnem območju. V prevodu je kulturno besedje tisti element, ki bralcu najbolj jasno nakazuje, da bere prevod. Alenka Bole Vrabec v primeru, ko gre za besedje, vezano na specifično kulturno okolje, prenese tuji kulturni izraz in ohranja španski zapis v poševnem tisku, v opombah pa razloži pomen večine teh izrazov. Zaznamo prevajalkino težnjo po potujevanju oziroma poudarjanju eksotičnosti besedilnega sveta. 